\title{
A memória, o equívoco e a reparação: uma análise sobre memória e o filme "Desejo e Reparação"
}

The memory, the mistake and The repair: an analysis about memory and the movie "Atonement" 


\section{Resumo}

Este artigo pretende, por meio da análise do filme "Desejo e reparação", baseado na obra de lan McEwan, estudar como, em uma narrativa fundamentada, as memórias exercem influência no destino dos personagens. $O$ estudo tomará como base uma das personagens protagonistas da história para, então, por intermédio de conceitos de memória, equívoco e reparação, entender os desdobramentos da narrativa. Em conclusão, pretende-se definir se, através de uma reparação, o uso da memória como forma de se desculpa pode ser a única forma de redenção da personagem.

Palavras-Chave: Desejo e reparação; Memória; destino; equívoco; reparação.

\section{Abstract}

This article will, through the analysis of the film "Atonement" based on the work of lan McEwan, study how can memories has influence on the fate of the characters in a narrative. The study will take as basis one of the protagonists of the story, then, through concepts of memory, misconception and repair, understand the unfoldings of the narrative itself. In conclusion, it is intended to define that, through repair, the use of memory as an excuse can be the only way for redemption of the character.

Keywords: Atonement; Memory; fate; mistake; repair.

ISSN: $1808-3129$

$1 \quad$ Mestrando em Comunicação Social pela FAMECOS - PUC/RS

Pontifícia Universidade Católica do Rio Grande do Sul - PUC/RS

brunocelidonio@yahoo.com.br 


\section{Introdução}

Para McEwan, em entrevista à revista Newsweek, "Reparação" é o seu "romance de Jane Austen" (GILES, 2002, p. 94). Porém mais que apenas um romance, este sétimo livro do autor, eleito o melhor do ano de 2002 pela revista Time e indicado ao Booker Prize é, através da visão cinematográfica de Joe Wright em 2007, um romance visceral e cruel, no qual uma mentira é capaz de modificar e destruir o futuro de um casal começando um relacionamento. Embora McEwan (2001) não tenha recebido o Booker Prize por sua obra, "Reparação" é unanimidade entre os críticos, de que este livro em especial é a obra-prima do escritor. Frank Kermode (2001) chama Reparação de virtuoso e o compara a Henry James e Ford Madox Ford, já que para o crítico, em Reparação "McEwan examinou este território (da fantasia e da realidade) com inteligência e atenção criativa, e poderia ser dito que nenhum contemporâneo seu mostrou tão apaixonada dedicação à arte do romance".

Assim, e como forma de entender essas características, é necessário abordar, através de um breve resumo e conceituação em linhas gerais, o enredo do filme que no Brasil recebeu o título de “Desejo e Reparação” (Atonement, dir. Joe Wright, 2007).

Briony, de 13 anos, é a filha mais nova da família Tallis e mora em um vilarejo nos arredores de Londres. Criativa e escritora nata, é solitária e se fecha em seu mundo organizado à exaustão e idealizado, de forma um tanto neurótica. Em um determinado dia do ano 1935, Briony presencia uma cena incomum: sua irmã mais velha, Cecilia, desnuda-se diante do filho de sua empregada, o protegido pela família Tallis, Robbie Turner, mergulhando em uma fonte d'água presente no jardim de sua casa. Confusa, Briony julga ter visto sua irmã humilhar-se submissivamente para o rapaz e, após ler sem permissão um bilhete enviado equivocadamente de Robbie para Cecilia, acredita ser ele um pervertido, que sempre enganou sua família. Durante um suntuoso jantar na casa de sua família, e como último fato para atestar o mau-caráter de Robbie, Briony flagra sua irmã mantendo relações sexuais escondidas com o rapaz na biblioteca da família. De posse destes acontecimentos e somado ao fato de que durante o jantar sua prima Lola foi violentada por um homem misterioso, Briony julga que o agressor foi Robbie. Este é condenado à prisão e, como forma de reduzir a pena, decide entrar para o exército britânico durante a Segunda Guerra Mundial. Passados os anos, Briony deseja perdão e redenção perante o mau (e errôneo) julgamento ao acusar Robbie e, assim, passa a escrever suas memórias de forma alterada da realidade, tentando trazer a reparação tão desejada por ela ao casal.

Sem tratar neste texto aquilo que se chama de spoilers, pode-se basear no entendimento de Azevedo (2009) o conceito que aborda a história como uma narrativa baseada na memória. Para o autor, a falsa acusação sobre Turner, amante da irmã de Briony, faz com que esta conviva com a culpa do erro e, consequentemente, tente redimir-se, mudando através de suas lembranças um novo passado e um outro final para a história:

Como o título sugere, o romance centra-se no esforço de sua protagonista de fazer reparações para as trágicas consequências do seu falso testemunho que envia Robbie Turner para a prisão. Briony é movida a escrever uma história que é tanto uma confissão da sua culpa, isto é, um relato factual de sua transgressão, e uma história 
O presente estudo não pretende fixar-se, assim, em uma análise fílmica, mas observar e buscar entender as motivações da personagem Briony tanto na obra de McEwan (2001) quando em sua adaptação para as telas através do filme "Desejo e Reparação" de John Wright (2007), a fim de encontrar, com base em uma pesquisa bibliográfica, respostas para o porquê do uso da memória como fator de reparação. A presença da memória neste romance representa mais que apenas lembranças propriamente ditas. Aqui, funciona como peça fundamental para a trama, uma vez que é através das memórias da personagem Briony que o enredo se transforma, desde as mais doces, de quando era criança, no lago, fantasiando sua relação com Robbie, ou nas que o transformam em um criminoso, até seu desejo de resgatar essas memórias, e tentar modificá-las como forma de sanar seus erros de julgamento do passado. Assim, se está presente a tríade no filme "Desejo e Reparação", foco de análise deste estudo: A memória propriamente dita, o equívoco (como uma memória ilusória ou fictícia) e a reparação através da memória.

\section{Memória e equívoco}

A história em análise baseia-se na força do arrependimento, da culpa e do amor, nos quais a personagem sofre tentando reparar seu erro, penitenciando-se pelo seu mau julgamento. Assim, o sentimento de culpa e a tentativa de sua reparação após este erro são bastante evidentes em cada cena em que a personagem vem a aparecer, tanto nas páginas do livro, quanto em tela. No que tange ao filme, entretanto, é em seus relatos que podemos observar a força de sua memória como ponto chave para o desenrolar da trama, e é através dela (seja a lembrança verdadeira ou ilusória) que os acontecimentos ocorrem. Pode-se identificar portanto, e de acordo com o desenrolar da trama, os três tipos de memórias já aludidos acima, presentes constantemente na história.

Seguindo este rumo científico, para Le Goff (2003) o conceito de memória seria a propriedade de conservar informações, através de funções psíquicas, a partir das quais atualizamos impressões ou informações passadas ou, então, que representamos como passadas. Ainda neste viés, pode-se definir memória como a capacidade que o sistema nervoso tem para adquirir e reter habilidades e conhecimentos úteis, permitindo que os organismos vivos se beneficiem de suas experiências prévias (GAZZANIGA; HEATHERTON, 2003, p. 252). Assim, a memória seria caracterizada pela codificação, aquisição, formação, armazenamento, conservação e evocação de informações (IZQUIERDO, 2011, p. 11). Baddeley (1993), por sua vez, afirma que sem a memória, entretanto, haveria incapacidade de ver, escutar ou pensar e, ainda, não se teria uma linguagem ou um sentido de identidade das pessoas.

Muito embora fundamentais para o seu entendimento, nesta análise, e de forma mais subjetiva, outros conceitos melhor se adequariam ao tipo de memória da personagem Briony, saindo-se da esfera científica e se aproximando mais das emoções.

Walter Benjamin (1994) trata de memória de uma forma metafórica, mas nem por isso sem carregar de conteúdo capaz de defini-la. Em seu conceito, a memória seria 
a busca de fatos, esmiuçando o passado, comparando a memória a um processo de escavar terra, onde o quão mais fundo se vai, mais se descobre. A personagem busca em suas memórias, durante a primeira parte do filme, situações e lembranças que comprovem a reciprocidade de sentimentos entre ela e Robbie, indo cada vez mais fundo em acontecimentos passados. Assim, as atitudes dela vão ao encontro ao que diz Benjamin, ou seja, de que

quem pretende se aproximar do próprio passado soterrado deve agir como um homem que escava. Antes de tudo, não deve temer voltar sempre ao mesmo fato, espalhá-lo como se espalha a terra, revolvê-lo como se revolve o solo. Pois 'fatos' nada são além de camadas que apenas à exploração mais cuidadosa entregam aquilo que recompensa a escavação. (BENJAMIN, 1994, p. 239).

Bergson (apud BOSI, 1999) afirma que o passado, ao entrar em contato com o presente, misturaria-se com as percepções imediatas, deslocando-as. Assim, todas memórias da personagem Briony, quando na presença de Robbie, mesmo que de caráter infantil, misturariam-se com seus novos sentimentos, já que agora com 13 anos a descoberta da paixão se tornaria mais incidente em suas memórias infantis. Continua o autor a explicar que este deslocamento faz com que a memória seja, além de uma força subjetiva, acima de tudo invasora, aprofundando o sentimento original. Explicaria assim o porquê de ser, para a personagem, tão difícil enxergar algo de forma diferente do que de fato ela relatou quando sua prima foi violentada. Briony possuía memórias recentes (não entrando aqui no mérito de seu equívoco) de seu afeto ou amor ilusório estar lhe traindo com sua própria irmã. Estas memórias então acabam invadindo seu sentimento original, incidindo e nublando seu relato sobre os fatos ocorridos. Para ela, se suas memórias indicavam que Robbie seria um depravado sexual, logo ele seria o culpado pelo ato de violência. Este sentimento (ou sensação) seria, então, um diálogo entre a razão e os sentidos. (DE CARLI, 2002, p. 139)

Duas passagens do filme explicitam este diálogo entre a razão e o sentido da personagem, com a clara invasão da memória no sentimento original. Em um determinado momento já aludido em resumo da trama, Briony observa Cecília então despindo-se para Robbie e entrando em uma fonte nos jardins em frente à casa de sua família. Neste momento, em sua percepção, Cecília estaria se humilhando perante Robbie. A realidade, demonstrada através do ponto de vista do casal, é completamente diferente. Cecília entra na fonte para buscar um pedaço de vaso que Robbie havia quebrado ao discutir anteriormente com ela. Briony não presencia a cena, nem a observa de sua janela.

Já a segunda passagem é mais traumática. Através do envio de um bilhete pessoal que deveria ser um pedido de desculpas pelo vaso, Robbie entrega a Briony um bilhete para que ela o leve até Cecília, porém por engano um de cunho erótico, escrito para Cecília em um momento de desabafo, e não o de pedido de desculpas. A personagem infringe as regras sociais de sigilo, lê o bilhete e, num misto de choque e desilusão, assume pela primeira vez que o rapaz seria um depravado sexual. Tal assunção se torna latente e se confirma em sua cabeça quando flagra, na biblioteca, o casal mantendo relações sexuais, na noite do jantar de sua família. É tomada desses acontecimentos que, quando busca em suas memórias base para relatar o crime ocorrido, julga Robbie 
como culpado. A cena em questão é melhor explicada em passagem do livro, que não se difere muito do conteúdo cinematográfico, como segue:

Embora estivessem imóveis, sua percepção imediata era de que havia interrompido um ataque, uma luta corporal. A cena era uma concretização tão cabal de seus piores temores que ela teve a impressão de que sua imaginação excitada havia projetado aquelas figuras nas lombadas dos livros nas estantes.Essa ilusão, ou esperança de ilusão, dissipou-se assim que sua vista se adaptou à penumbra. Ninguém se mexia. Briony olhou por cima do ombro de Robbie e viu os olhos apavorados de Cecilia. Ele havia se virado para trás para ver quem tinha entrado, mas não soltou Cecilia. Apertara seu corpo contra o dela, levantando-lhe a barra da saia acima do joelho, e a encurralara no ângulo reto formado pelas estantes. Com a mão esquerda atrás da nuca da moça agarrava-lhe o cabelo, com a direita, segurava-lhe o braço esguio num gesto de protesto, ou de auto defesa. Ele parecia tão forte e feroz, e Cecilia, ombros nus e braços finos, tão frágil, que Briony não tinha idéia do que lhe seria possível fazer quando partiu pra cima deles. Queria gritar, porém estava sem fôlego, e sua língua estava lenta e pesada. Robbie movimentava-se de tal modo que a impedia completamente dever a irmã. Em seguida, Cecilia tentou se livrar, e logo ele a soltou. Briony parou e pronunciou o nome da irmã. Quando Cecilia passou por Briony, não havia nela nenhum sinal de gratidão, de alívio. Seu rosto não tinha nenhuma expressão, estava quase tranqüilo, e ela olhava diretamente para a porta pela qual ia sair. Então saiu, e Briony ficou sozinha com Robbie. Também ele não quis encará-la. Em vez disso, olhava para o canto, enquanto ajeitava o paletó e a gravata. Desconfiada, a menina foi andando para trás, afastando-se, porém ele não fez nenhum gesto ameaçador, nem sequer olhou para ela. (McEWAN, 2002, p. 151-152)

Porém uma outra forma de responder esse equívoco, contudo, poderia estar presente nas definições de memória e sentidos vitais através das idéias de Schmitt (2001). O autor salienta que estímulos são sensações guardadas pelo cérebro humano ou, em outras palavras, que a memória armazenaria informações através de sensações que se sobressaíssem das demais e, assim, seria sensacional um estímulo mesmo que este produzisse uma sensação fictícia. Visto isso, poderia resultar até em uma ilusão e, desta forma, a memória da personagem seria afetada por um sentimento mais forte, o que geraria seu equívoco.

Considerando-se o disposto acima e se estar diante de uma memória falha, com características irreais ou fictícias, o relato do ocorrido estaria sendo invadido, ainda, de emoções.

Como forma de definição, e se baseando nos conceitos elaborados por Russel (1980), a emoção pode ser entendida como "a composição de dimensões fundamentais de alerta (do relaxado ao estimulado) e valência (do desagradável ao agradável), em uma concepção definida como a teoria dimensional da emoção". Desta forma, pode-se dizer que Briony possuía emoções como raiva, inveja ou traição incidindo em suas memórias e, assim, corrompendo a realidade dos fatos. Porém a emoção não é o único fator que poderia afetar sua memória. Outros fatores cognitivos, somados a anatômicos, fisiológicos e sociais, somados ao meio e a cultura, poderiam gerar estes resultados. Briony poderia ser esquizofrênica, e em momento algum a história estaria desmentindo este fato. Sua família, através de doutrina, educação ou vivência, poderia ter estimulado a jovem a fazer as ligações de que, por Robbie manter relações sexuais com Cecilia, e ela, uma criança de treze anos, presenciar tal ato, deveria ver isso como distúrbio, doença, perversão. Não haveria, em qualquer parte do filme, fato que des- 
mentisse estes dados. Somadas estas possibilidades, por sua vez, a emoção não afetaria sozinha a memória, mas estaria (ou não) vinculada a uma gama de fatores capazes de afetá-la. (CHRISTIANSON, 1992; SCHACTER, 1995).

Uma vez estas emoções, provavelmente, estarem se somando a outros fatores que afetam a memória, poderiam até atuar como forma de melhorar a retenção, mas também poderiam induzir em um erro ou equívoco, e a memória sofreria influência passando a ser prejudicial, ou seja, fantasiosa.

Uma mentira.

Estaria a personagem mentindo sobre o ocorrido com sua prima ou apenas cometendo um equívoco?

Esta definição de memória irreal ou fantasiosa tem como base um dos conceitos de mentira. Conforme Skinner (1957), ao analisar o relato verbal que materializa a mentira, se teria sob si o controle de um estímulo antecedente não verbal como reforçadores generalizados, podendo não corresponder ao estímulo antecedente. Assim, duas hipóteses poderiam ser levantadas para explicar este fato: falsas memórias ou mentira. No primeiro caso se estaria em frente ao controle de estímulo distorcido ou sob controle de estímulos irrelevantes. Numa segunda hipótese, o relato do indivíduo não está sob controle do estímulo antecedente, mas sim, de conseqüências específicas e, portanto, o relato teria função de esquiva. Ora, em momento algum a personagem quer se esquivar ou resultar algum mal. Suas memórias, aqui, traem seus relatos, mantendo o controle de seus estímulos e a induzindo ao erro. Não se pode falar que Briony mentiu, apenas foi induzida a erro graças a emoções inseridas em suas memórias. Não havia dolo, nem mesmo eventual.

E porque a personagem mantém seu equívoco, mesmo após iniciar o processo de arrependimento?

A inserção de emoções nas memórias, conforme já comentado anteriormente, pode induzir ao erro, mas são esses mesmos sentimentos que fazem com que a personagem não mude suas convicções, mesmo quando ela lida, por anos, com a dúvida. É interessante observar que a emoção de Briony se aproxima muito ao ressentimento. Tal emoção é de difícil definição, conforme ensina David Konstan (2001) e, neste caso, buscando-se um dos possíveis sentidos presentes na definição do autor, o psicológico seria o mais correto de se atribuir à personagem. Este sentido faz parte de um conceito tríplice do termo (sentimento psicológico, social e existencial), e no caso estaria se referindo não apenas a algo como a raiva ou irritação, mas mais que isso, à situações em que alguém se sentisse ferido, ofendido ou injuriado pela ação do outro e, de forma raivosa, tomasse o tempo, não sendo fugaz, mas lento e duradouro, sem desaparecer por completo com o passar dos anos.

[Ressentimento é] uma atitude mental duradoura, causada pela repressão sistemática de certas emoções e afetos que são componentes normais da natureza humana. A repressão dessas emoções leva a uma tendência constante de se permitir atribuir valores incorretos e juízos de valor correspondentes. As emoções e afetos primordialmente referidos são vingança, ódio, malícia, inveja, o impulso a diminuir e desprezar. (SCHELER apud BRESCIANI; NAXARA, 2001) 
Assim, a manutenção do equívoco da personagem passa por diversos estágios, iniciando com o ressentimento, passando pelo arrependimento, dor, até chegar na culpa. Aqui, então, a memória é elucidada, se despe de emoções capazes de induzir ao erro e fica clara. Briony só chega nesse estágio ao saber do casamento de sua prima com um convidado daquela mesma janta, naquela mesma noite em que sua prima foi violentada, fazendo a junção dos fatos existentes em sua memória, de sua prima, do convidado e da violência, e enfim consegue, claramente, entender quem foi o real agressor.

Cometeu um equívoco.

Cabe agora, arrependida, reparar os danos causados.

\section{Reparação}

A reparação propriamente dita seria, por definição, o ato ou efeito de reparar (MICHAELIS, 1998). Seu sentido figurado adquire um viés de retratação de palavras injustas ou ofensivas, e nem sempre a reparação limita-se aos danos morais, podendo se caracterizar como indenização por danos materiais, por exemplo. De forma mais ampla, a reparação pode se dar pela simples resposta, adicionada ou não de indenização, desde que repare os danos causados. Mais importante para este estudo se dá na definição para McEwan, ou seja, o que ele entende por reparação, uma vez que ela acontece no plano dos fatos, ou seja, no que se entende por real e objetivo. Assim, o dano causado é reparado, tentando-se voltar ao chamado status quo ante, isto é, ao que era antes do prejuízo propriamente dito.

Segundo Klein (1937), as tendências de reparação se desenvolvem na interação com os impulsos destrutivos presentes na relação entre amor e ódio, e assim lutam entre si na mente e, de certa maneira, pelo resto da vida, podendo se tornar fonte de perigo nas relações humanas.

Ainda, no que tange ao tempo, tais emoções ocorrem no presente, não se pode reparar no futuro ou alterando o passado, mas transformar no presente o futuro, como acredita Benjamin (1994). Para ele o agora é o lugar e a ocasião em que o passado e o futuro visam um ao outro, onde eles se tocam, convergem, e não seria o ponto a partir do qual divergem. Assim, o presente é a realidade, de aprendizado e construção. Porém não seria possível modificar tanto o passado quanto o futuro senão no presente e, sendo assim, apenas se trataria então do plano objetivo, ou seja, do que se chama de plano fático ou dos fatos.

No entanto Briony, com seu equívoco, criou consequências incapazes de reparação. Suas memórias falhas e viciadas a levaram a destruir o futuro de Robbie e de sua irmã Cecilia. Não há ato, indenização ou resposta que possam trazer seu amor ilusório ou sua irmã de volta. E por isso não existiria forma de se reparar os danos, ao menos no que tange ao plano objetivo, real e fático.

A forma encontrada é a reparação no plano subjetivo, irreal, através da própria criação de memórias, e assim adicionar uma emoção (arrependimento) para que, ao menos ali, a reparação se fizesse possível. Briony sabia ser impossível reparar os danos causados à sua família e às pessoas, mas em suas próprias memórias encontrou uma 
forma de sanar os danos causados, mesmo que com ilusões, a Cecilia e Robbie.

Agrada-me pensar que não é por fraqueza nem por evasão, e sim como um gesto final de bondade, uma tomada de posição contra o esquecimento e o desespero, que deixo os jovens apaixonados viver e ficar juntos no final. Dei-lhes a felicidade, mas não fui egoísta a ponto de fazê-los me perdoar. Não exatamente, não ainda. (McEWAN, 2002)

Volta-se então ao que se entende por memória com características irreais ou fictícias, através de emoções. Porém desta vez a emoção somada à memória não resultaria em um erro ou uma falha, mas a única forma de trazer, mesmo no plano subjetivo, o que originalmente poderia ter sido a realidade. Somado a esta dualidade de planos fático e irreal e, como uma forma extra na imaginação da personagem, o destino imaginado seria muito além da possível realidade, definindo um estado irreal de felicidade plena, de justiça feita, de absolvição dos erros. Como resultado, é escrito um livro, onde a personagem relata seu tão desejado encontro com o casal, tendo a chance de pedir finalmente perdão, deixando-os livres finalmente para seguirem seus caminhos, viverem juntos e serem felizes.

A realidade, entretanto, é mais chocante.

No plano objetivo, ambos Robbie e Cecilia estão mortos, nunca tiveram a chance de ser felizes, nem de se reencontrarem, e muito menos Briony teve a chance de, em um encontro, pedir desculpas por seu equívoco. A reparação ocorre apenas na ficção, de forma egoísta, para absolver qualquer erro ocorrido, criando novas memórias e agindo na consciência da própria causadora do prejuízo, e sem resultado algum na vida dos sofredores do dano.

\section{O perdão ou considerações finais}

A idéia inicial deste estudo foi analisar, através principalmente das teorias sobre memória, a história de "Desejo e Reparação", baseado na obra lan McEwan (2001). Antes de qualquer certeza final, existem motivações que levaram este estudo a tratar de memórias como base da pesquisa. O filme foi visto diversas vezes, o livro lido e relido, e sempre se chegou à conclusão de que a "mentira" de Briony havia resultado em um desastre sem proporções na vida de sua irmã e do personagem Robbie. Nem a auto-penitência da personagem, tentando reparar seus erros, parecia retirar dela a culpa do desfecho da história.

Porém sempre houve algo que criava curiosidade, uma dúvida. Será que a personagem realmente mentiu, ou ela se equivocou, teve uma falha de juízo? Como se poderia eximir a culpa da tragédia, e encontrar um porquê que explicasse e justificasse suas ações?

A mentira é descartada se observardo o relatado acima, de que ao se misturar às memórias de Briony suas emoções, estas mascaram aquelas e, consequentemente, incidem sobre o juízo de valor, podendo ter levado a personagem a se equivocar e criar, em sua cabeça, uma situação que nunca ocorreu.

Assim, mesmo não tendo como se definir quem fugiu nos jardins naquela noite do 
crime, pelo que a memória da personagem alertava ao ser deslocada com a emoção, é de que Robbie seria esta pessoa.

Porém mais profundo é o dilema da reparação através da memória. Em realidade isso não existiria, uma vez que não sanaria no plano real todos os danos (morais e materiais) causados. Ainda, não há como entender ao fim que o ato de reparar apenas em suas memórias não fez de Briony uma pessoa egoísta, já que somente em sua imaginação a história do casal teria um desfecho feliz e, através disso, ela criaria uma fantasia para sua própria redenção. Por outro lado, é apenas por intermédio desse plano subjetivo e do uso da memória que poderia se intentar uma desculpa, pois parece esta ser a única solução para que finalmente a personagem seja absolvida de seus equívocos.

Portanto, mesmo que na realidade seja impossível, é apenas na ficção, no egoísmo e nas memórias de Briony que o casal Robbie e Cecilia teriam a possibilidade de reparação, e assim um final feliz.

\section{REFERÊNCIAS}

Atonement. Dir. JoeWright. Perf. Keira Knightley and James McAvoy. 2007. DVD. Universal, 2008.

AZEVEDO, M. M. Memory and Forgetfulness in lan McEwan's Atonement. In: 20 Congresso Internacional da ABRAPUI, 2009, São José do Rio Preto: ABRAPUI, 2009. Anais do II Congresso Internacional da ABRAPUI, 2009.

BADDELEY, A.D. Your Memory: A User's Guide (2nd edition).London: Lifecycle Publications, 2009.

BENJAMIN, W. Rua de mão única: obras escolhidas II. São Paulo: Brasiliense, 1994.

BOSI, Ecléa. Memória e sociedade: Lembranças de velhos. 3.ed. São Paulo: Companhia das Letras, 1999.

BRESCIANI, Maria Stella Martins; NAXARA, Márcia Regina Capelari. Memória e (res) sentimento: indagações sobre uma questão sensível. Editora da UNICAMP, 2001.

CHRISTIANSON, S. The handbook of emotion and memory: Research and theory. Hillsdale: Erlbaum, 1992.

DE CARLI, Ana Mery Sehbe. O sensacional da moda. Caxias do Sul: EDUCS, 2002. GILES, J. A Novel Of [Bad] Manners. Newsweek. 08 de abril de 2002 IZQUIERDO, Iván. Memória. Porto Alegre: Artmed, 2011.

KERMODE, F. Point of View. London Review of Books. 4 de outubro de 2001.

KLEIN, M.; RIVIÈRE, J. Amor, ódio e reparação. Rio de Janeiro: Imago, 1975

KONSTAN, David. Ressentimento - História de uma emoção. In: BRESCIANI, Stella; NAXARA, Márcia. Memória e ressentimento. Campinas: UNICAMP, 2001.

LE GOFF, Jacques. História. In: LE GOFF, Jaques. História e memória. 5. ed. Campinas: Unicamp, 2003.

MCEWAN, Ian. Atonement. London: Vintage, 2007.

Reparação. Tradução de Paulo Henriques Britto. São Paulo: Companhiadas Letras, 2002. 
Michaelis: moderno dicionário da língua portuguesa. Melhoramentos, 1998.

RICCEUR, Paul. A memória, a história, o esquecimento. Campinas: UNICAMP, 2007.

RUSSELL, J.A. A circumplex model of affect. Journal of Personality and Social Psychology. Vol. 39, 1161 - 1178. (1980)

SCHMITT, Bernd. Marketing experimental. São Paulo: Nobel, 2001.

SCHACTER, D. L. Memory distortion: History and current status. In: SCHACTER D. L.; COYLE, J. T.; FISHBACH, G.D.; MESULAM, M.; SULLIVAN, L. E. Memory distortion: How minds, brains, societies reconstruct the past. Cambridge: Harvard University Press, 1995.

SKINNER, B. F. Verbal Behavior. New York: Applenton-Century-Crofts, 1957.

TEDESCO, João Carlos. Nas cercanias da memória: temporalidade, experiência e narração. Passo Fundo: EDUCS, 2004

TURK, D.J., HEATHERTON, T.F., MACRAE, C.N., KELLEY, W.M., \& GAZZINIGA, M.S. Out of contact, out of mind: The distributed nature of self. Annals of the New York Academy of Sciences.1001, 65-78. (2003) 